\title{
MODELOS DE CADEIAS DE LAÇO FECHADO NA INDÚSTRIA DE IMPRESSÃO
}

\section{CLOSED LOOP SUPPLY CHAIN IN PRINTING OPERATION}

\author{
Marcius Fabius Carvalho* - marcius@puc-campinas.edu.br \\ Reinaldo Daniel Fioravanti** - reinaldo fioravanti@yahoo.com \\ *Orlando Fontes Lima Junior** - oflimaj@fec.unicamp.br \\ ${ }^{*}$ PUC-Campinas, Campinas, SP \\ **Laboratório de Aprendizado em Logística e Transporte - LALT, UNICAMP, Campinas, SP
}

\begin{abstract}
Resumo: As empresas de grande porte, antes voltadas primariamente para a produção de bens, reposicionam-se, buscando oferecer serviços como forma de aumento de competitividade. Ao mesmo tempo, elas se deparam com um aumento de produtos que retornam dos consumidores por diversos motivadores, impulsionando a aplicação das práticas de gerenciamento da logística reversa e introdução da visão da gestão da Cadeia de Laço Fechado (CLF) ou Closed Loop Supply Chain. Este artigo tem como propósito, por meio de um estudo de caso no setor de impressão, identificar as principais características quanto ao fluxo de retorno de produtos, sendo uma operação focada em varejo e outra, em serviços. Adicionalmente, também se realiza um diagnóstico das práticas, da visão e aplicação dos modelos de CLF nos dois modelos operacionais. Com este trabalho, conclui-se que há diferenças acentuadas no gerenciamento da CLF nos dois modelos de operação em varejo e em serviço e identificam-se as principais brechas em cada uma delas.
\end{abstract}

Palavras-chave: Cadeias de Suprimentos. Cadeias de Suprimentos de Laço Fechado. Logística Reversa. Estratégia. Serviço ao Cliente.

Abstract: There is a clear change in focus in large companies, previously dedicated primarily to the production of physical goods, toward offering complimentary services and changing their focus toward more service-oriented businesses, in order to increase their competitiveness. At the same time, companies are facing increasing product returns due to various reasons leading to reverse logistics practices and toward the introduction of a Closed Loop Supply Chain management perspective. The purpose of this work is to identify, using a case study in the printing industry, specific characteristics, regarding product returns, both in a product-oriented and a service-oriented operation. Furthermore, the current work performs a diagnosis of current practices applications of CLSC models in the two operating models. The paper concludes that indeed there are relevant differences in managing the CLSC for each case and identify the main gaps for each operation.

Keywords: Supply Chain. Closed Loop Supply Chain. Reverse Logistic. Strategy. Service Level.

\section{INTRODUÇÃO}

Em uma Cadeia de Suprimentos Direta, o consumidor é tipicamente o fim do processo. Tomando esse ponto como base, cadeias de suprimento podem ser 
definidas como sistemas constituídos de fornecedores de materiais, recursos de produção ou montagem, serviços de distribuição e consumidores ligados pelo fluxo de material e de informação (STEVENS, 1989; LEE et al., 1997). Envolvem, em um ambiente globalizado, desde processos de manufatura de uma mesma unidade produtiva até unidades de negócio que possam estar situadas em diferentes países. Tais unidades e processos devem ser gerenciados, considerando a coordenação entre operações e funções múltiplas de empresas independentes, contudo engajadas na proposta de entrega do produto ou serviço a um consumidor final.

A Gestão da Cadeia de Suprimentos (GCS) é o conjunto de enfoques e estratégias para integrar eficientemente fornecedores, fabricantes, distribuidores, transportadores e consumidores de forma que os bens sejam produzidos e distribuídos nas quantidades, horas e locais certos, minimizando custos ao mesmo tempo que atinge o nível de serviço desejado pelos clientes (SIMCHI-LEVI, 2000, p. 27).

Embora as cadeias produtivas existam há longa data, somente a partir do final dos anos 90 do século passado, a GCS passou a tomar parcela significativa da agenda e investimentos nas áreas de operações nas empresas, tornando-se prioridade o gerenciamento eficiente de todos os elos e relacionamentos entre os parceiros na busca constante de melhor solução para equacionar competitividade e lucro (MOLLENLOPF; CLOSS, 2005). Acrescenta-se a esse gerenciamento um novo desafio, ou seja, a extensão para além do ponto de venda, considerando-se o ciclo completo do produto desde sua criação até o descarte adequado resultante da preocupação com o impacto ambiental. A Cadeia de Suprimentos que incorpora o ciclo completo do produto, ou seja, as ações da Cadeia Direta e as adicionais da Cadeia Reversa, (GUIDE et al., 2003) recebe a denominação de Cadeia de Suprimentos de Laço Fechado (CSLF). A partir da criação do conceito, poderão ser estabelecidas políticas de recuperação de itens reutilizáveis em consonância com políticas de entrega de produtos novos (KONSTANTARAS; PAPACHRISTOS, 2008).

Este trabalho tem por objetivo discutir os conceitos, as melhores práticas e os quatro direcionadores (Legislação, Imagem, Serviço ao Cliente e Benefícios Econômicos) no gerenciamento da Cadeia Reversa e identificar as principais características quanto ao fluxo de retorno de produto para um ambiente de serviços de uma empresa que atua no mercado de impressão, produzindo e comercializando 
produtos tanto para o mercado corporativo quanto para o mercado varejista. No mercado corporativo, a empresa oferece o serviço de gerenciamento do parque de impressoras atendendo às normas ambientais do cliente e do produto, assumindo a responsabilidade pela operação de take back ao final do contrato ou da vida útil do equipamento. No setor varejista, analisa as várias estratégias de recuperação do retorno, desde a inconsistência na entrega até o fim da vida útil do equipamento.

A relevância do tema é destacada por uma pesquisa realizada em 160 empresas de computadores, produtos eletrônicos, Telecom, aeroespacial e indústrias de manufatura, que aponta para um aumento em $7 \%$ da satisfação do cliente, diminuição da média de 14,5 dias para 4,4 dias para o retorno do produto e melhoria em $21 \%$ do custo por material em retorno para aquelas empresas que utilizam os procedimentos Best-in-class de logística reversa (RYDER, 2011). Estes números apontam para grandes benefícios obtidos quando o fluxo reverso é tratado como parte integrante do conceito de Cadeia de Suprimentos de Laço Fechado.

O trabalho apresenta, a seguir, o conceito de Cadeias de Suprimento de Laço Fechado e a abrangência do problema de retornos dentro de uma empresa, discutidos na seção três. Os direcionadores para o estabelecimento de uma estratégia de recuperação dos retornos são discutidos na seção quatro, enquanto a discussão da perda de valor marginal do produto com o tempo é apresentada na seção cinco. A seção seis apresenta a metodologia para o estudo de caso nas operações de varejo e serviço. Por fim, considerações e recomendações devidas.

\section{A CADEIA DE SUPRIMENTO DE LAÇO FECHADO (CSFL)}

A Gestão da Cadeia de Suprimentos consiste na colaboração entre empresas para impulsionar o posicionamento estratégico e melhorar a eficiência das operações (BOWERSOX, CLOSS e COOPER, 2008, p. 4). Segundo Pires (2004,62), a Gestão da Cadeia de Suprimentos poderá, também, ser vista como uma expansão natural e necessária da gestão da produção e de materiais para além dos limites físicos da empresa. Como resultado, a GCS é multiempresarial e multifuncional, incorporando diversas áreas como produção, logística, marketing e compras. Considerando as duas definições acima, a Gestão da Cadeia de Suprimentos é um processo que ultrapassa as barreiras de uma empresa para 
gerenciar todo o processo de negócio nas atividades de compra e produção, entrega de produtos e serviços ao cliente final, incluindo subfornecimentos, fornecimentos, operações internas, grandes consumidores, varejistas e consumidores finais. Para que haja uma gestão adequada, são necessárias ações para integração dos sistemas de informação, produção e controle do fluxo de material dentro e entre empresas participantes da cadeia (SIMCHI-LEVI et al., 2000, p.38).

Tem sido reconhecida, contudo, uma necessidade de extensão da cadeia além do ponto de venda, no intuito de considerar a fase de utilização do produto (i.e., serviço, manutenção e outros) e a fase após o uso. Nessa direção, Guide et al. (2003) alertam que as empresas precisam de um enfoque de ciclo de vida para os produtos que integrem o retorno (retorno comercial, garantia, reparo, retorno de fim de uso e retorno de fim de vida) em um modelo de negócio. A importância do enfoque vem aumentando à medida que os produtos têm o ciclo de vida diminuído e, por conseguinte, seu valor mais sensível ao tempo (GUIDE, et al. 2003). A Cadeia do Retorno ou Reversa é aquela composta por empresas e atividades que tratam do fluxo do produto no sentido a montante do cliente final. Segundo Guide et al. (2002), Cadeia de Suprimento Reversa é o conjunto de atividades necessárias para resgatar um produto usado de um cliente, reutilizá-lo ou descartá-lo. Ao gerenciamento do retorno, considerando as atividades de movimentação e as relações entre as empresas participantes, dá-se o nome de Gerenciamento da Cadeia Reversa (GCR). Assim, o GCR vai além da logística reversa que se preocupa com a movimentação do retorno tanto na cadeia direta quanto nas cadeias envolvidas com o retorno, por considerar a relação e responsabilidades das empresas envolvidas. No entendimento de Lebreton (2007, p.17), a Cadeia de Suprimento de Laço Fechado é a Cadeia Reversa interessada na reintegração de forma competitiva dos itens recuperados. Ainda, segundo o autor, após os itens recuperados terem sido filtrados, é necessário escolher duas das seguintes alternativas: a desmontagem e a canibalização. A desmontagem consiste na remoção de todas as partes dos produtos retornados e reintegração destas ao processo de montagem, enquanto a canibalização é uma desmontagem seletiva (LEBRETON, 2007, p.17). 


\section{ABRANGÊNCIA DO PROBLEMA DA CSLF}

A preocupação com este tema começa com o projeto do produto em que devem ser consideradas questões referentes a um "projeto ecológico", estabelecendo-se novos conceitos de produto e de produção. Incluem-se temas como consumo de energia, materiais usados, substâncias químicas, durabilidade, reuso e reciclagem, empacotamento e transporte, além das atividades de produção como a forma de mineração, forma de produção, submontagens e montagens (FERRENDIER et al., 2002).

A montagem modular, por exemplo, além de todas as vantagens introduzidas na Cadeia Direta, auxilia significativamente na recuperação do produto pela simples substituição de um módulo e a busca de um destino correto somente para a parte substituída. Outras técnicas de produção como o postponement podem contribuir para o aumento do valor do produto em retorno (AVIV; FEDERGRUEN, 2001).

O projeto do produto, a gestão adequada de seu fluxo até o destino final e oportunidades criadas pelo retorno tornam-se, portanto, muito importantes ao sucesso do negócio. O tratamento adequado do retorno, procurando rapidez do fluxo dentro de um processo de garantia ou contrato contribui, significativamente, para a satisfação e fidelização do cliente e imagem da empresa, além de ser necessário ao cumprimento das leis de defesa do consumidor e questões ambientais.

O volume, a relevância e a atenção dispensada no gerenciamento da Cadeia Reversa variam, contudo, para cada tipo de indústria, por seus produtos apresentarem características de volumes e custos diferentes. Enquanto em alguns setores, como editoras de livros e revistas, o volume de produtos retornados pode chegar a $50 \%$, em outros, como os de produtos de limpeza, apresentam volumes pequenos de retornos com baixo valor agregado. No primeiro caso, o gerenciamento da Cadeia Reversa deve estar incorporado ao negócio da empresa, o segundo, poderá não justificar igual ação (ROGERS; TIBBEN-LEMBKE,1998, p.27).

Para seu posicionamento, a empresa não pode esquecer-se de que está inserida em um ambiente altamente competitivo, em que há necessidade de redução de custos e aumento do nível de serviço, e de que o esforço empregado na imagem preservacionista do meio ambiente melhorará a competitividade do produto, mas deve ser acompanhado de outras ações que o viabilize economicamente. Além 
disso, o esforço de uma única empresa inserida no conceito de Cadeia de Suprimentos, não é suficiente, pois contando com diversos elos (extração, transformação, logística de distribuição e varejista), todos deverão estar alinhados com relação à cultura, objetivos e ações.

Em uma cadeia automotiva, os fornecedores de componentes são facilmente identificados. Participam também desse processo, empresas de apoio, como as de tecnologia de informação (hardware e software), que, no atendimento das necessidades da cadeia, geram retornos (computadores, impressoras, cartuchos), os quais devem ser tratados adequadamente. Uma empresa, para ter ações corretamente dirigidas no meio ambiente, necessita de que todo o ciclo de vida de seu produto fabricado siga o procedimento adequado. Deverá, também, cuidar para que seus fornecedores e clientes ajam da mesma forma, fazendo com que esse esforço ultrapasse suas fronteiras, tornando-se um problema multiproduto e multiestágio.

\section{DIRECIONADORES DA CADEIA DE SUPRIMENTO DE LAÇO FECHADO (CSLF)}

São quatro os direcionadores ou determinantes da Logística Reversa (LR): benefícios econômicos, legislação, imagem e serviço ao cliente. Como mostrado no Quadro 1, legislação e serviço ao cliente representam os direcionadores operacionais convencionais, enquanto retenção do cliente e fidelização podem transformar a gestão do retorno em estratégia do negócio, (RAJAGOPALAN, 2006, p. 22).

A primeira força direcionadora é a possibilidade de obtenção de lucro com a revenda do produto, quando este apresenta valor significativo após a primeira fase de uso. Nesse caso, os benefícios econômicos são vistos como a força direcionadora da logística reversa e estão relacionados com todas as opções de retorno em que a empresa recebe benefícios diretos ou indiretos. A logística reversa passa a ser uma atividade para recuperar investimento em oposição à visão de minimizar o custo do descarte. Esse é o caminho para produtos de ciclo de vida curto e inovação tecnológica (KRIKKE et al., 1999). 
Os benefícios da imagem social conduzem ao crescimento da imagem corporativa e tratam do conjunto de valores e princípios que impulsionam a organização a tornar-se responsavelmente engajada nas atividades de preservação do meio ambiente e de desenvolvimento sustentável.

A legislação que considera a obrigação de reciclagem e reuso do produto consumido ou de seus componentes com a finalidade de reintegrá-los no mesmo ou em outro processo refere-se a requisitos legais que obrigam a empresa a tornar-se responsável pela atividade de recuperação de seu produto. Essa atividade pode incluir a coleta e reuso de produtos após o ciclo de vida, atribuindo ao produtor o custo da gestão do descarte. Estabelece, também, restrições ao uso de substâncias no processo de produção que facilitem o desmanche e a reciclagem, por exemplo, do descarte eletrônico.

Quadro 1 - Direcionadores da Logística Reversa.

\begin{tabular}{|l|ll|}
\cline { 2 - 3 } Externa & Legislação & Imagem \\
Leis do governo & Retenção do consumidor \\
Leis específicas & Fidelização \\
Regras da Empresa com relação & Análise de mercado \\
ao retorno & Benefícios para a sociedade \\
Serviço ao Cliente & Benefícios Econômicos \\
Retornos em garantia & Redução do custo de Descarte \\
Novos Mercados & Retornos pelo reuso \\
Competitividade & Recuperação de produto e \\
Descarte & valor \\
\cline { 2 - 3 }
\end{tabular}

Operacional

Estratégica

Fonte: Adaptado de Rajagopalan (2006, p. 22)

A legislação pode estabelecer que determinados produtos eletrônicos, ao final do ciclo de vida, sejam retirados de acordo com procedimentos estabelecidos. Por esse direcionador, a recuperação do produto e o reprocessamento devem ser projetados visando ao custo mínimo.

As iniciativas de serviço ao consumidor reconhecem que a voz desse consumidor é o direcionador mais importante da cadeia reversa. A adoção da logística reversa traz, por sua vez, vantagem competitiva e fidelização para a 
empresa que incorpore metas ambientais em suas práticas de negócio e planos estratégicos.

Os temas ambientais ocupam cada vez mais espaço em todo o tipo de mídia, expressando posicionamento da sociedade por uma consciência ecológica e de governos com relação a um futuro sustentável. As empresas podem assumir dois posicionamentos referentes a tais temas, isto é, seguir as legislações vigentes ou tomar atitude proativa, antecipando comportamentos com o objetivo de melhoria da imagem corporativa de preservação e melhoria do meio ambiente. As legislações de defesa do consumidor, as regulamentações ambientais estabelecem o limite mínimo para o posicionamento das empresas com relação à responsabilidade sobre o destino de seu produto desde o momento da fabricação até o descarte adequado. Cabe à empresa posicionar-se, realizando este mínimo ou assumindo maiores responsabilidades com relação ao meio ambiente.

\section{GERENCIAMENTO DE RETORNOS}

\subsection{Configuração para o Tratamento do Retorno}

O primeiro passo, logo após a identificação dos objetivos do gerenciamento da Cadeia Reversa, é o entendimento das origens ou dos fatos causadores dos retornos e, a seguir, estabelecer a configuração para o tratamento. Segundo Blackburn et al. (2004), as principais atividades relacionadas ao retorno de material visando à recuperação de valor do produto são:

- $\quad$ Aquisição do produto: obtenção ou recebimento do produto do usuário.

- Logística reversa: transporte do produto para o ponto de inspeção; classificação e descarte.

- Inspeção e descarte: Verificação da condição do produto e tomada da decisão para reuso.

- Remanufatura: Recomposição do produto a sua especificação original.

- $\quad$ Marketing: Criação de mercado ao produto recuperado.

Os clientes retornam os produtos ao varejista (ponto de aquisição), que os envia ao ponto de avaliação dos retornos. Esse ponto terá de creditar os valores correspondentes ao retorno aos pontos de venda, realizar a inspeção e a Revista Produção Online. Florianópolis, SC, v.11, n. 4, p. 921-949, out./dez. 2011. 
distribuição conforme a condição do produto retornado. A manufatura precisará disponibilizar um procedimento de teste e diagnóstico que identifique, para cada caso, qual a ação que resultará em maior valor de retorno (ou menor custo de descarte). Um produto recuperado pode ainda não ter sido usado e, portanto, deve ser encaminhado novamente ao canal de distribuição. Fazem parte desse caso as realocações de estoques, Figura 1.

Outros produtos têm condição de ser remanufaturados e voltar ao canal direto de distribuição, por exemplo, em um mercado secundário para clientes que não queiram ou não possam comprar um novo. Os produtos sem condição de reuso ou de remanufatura deverão ser fisicamente destruídos. Alguns, com peças aproveitáveis, poderão suprir o mercado de garantias, que é o caso do setor eletrônico (FIORAVANTE; CARVALHO, 2008). Outros deverão ser descartados corretamente, portanto não contribuem para o que é considerado Cadeia de Suprimentos de Laço Fechado.

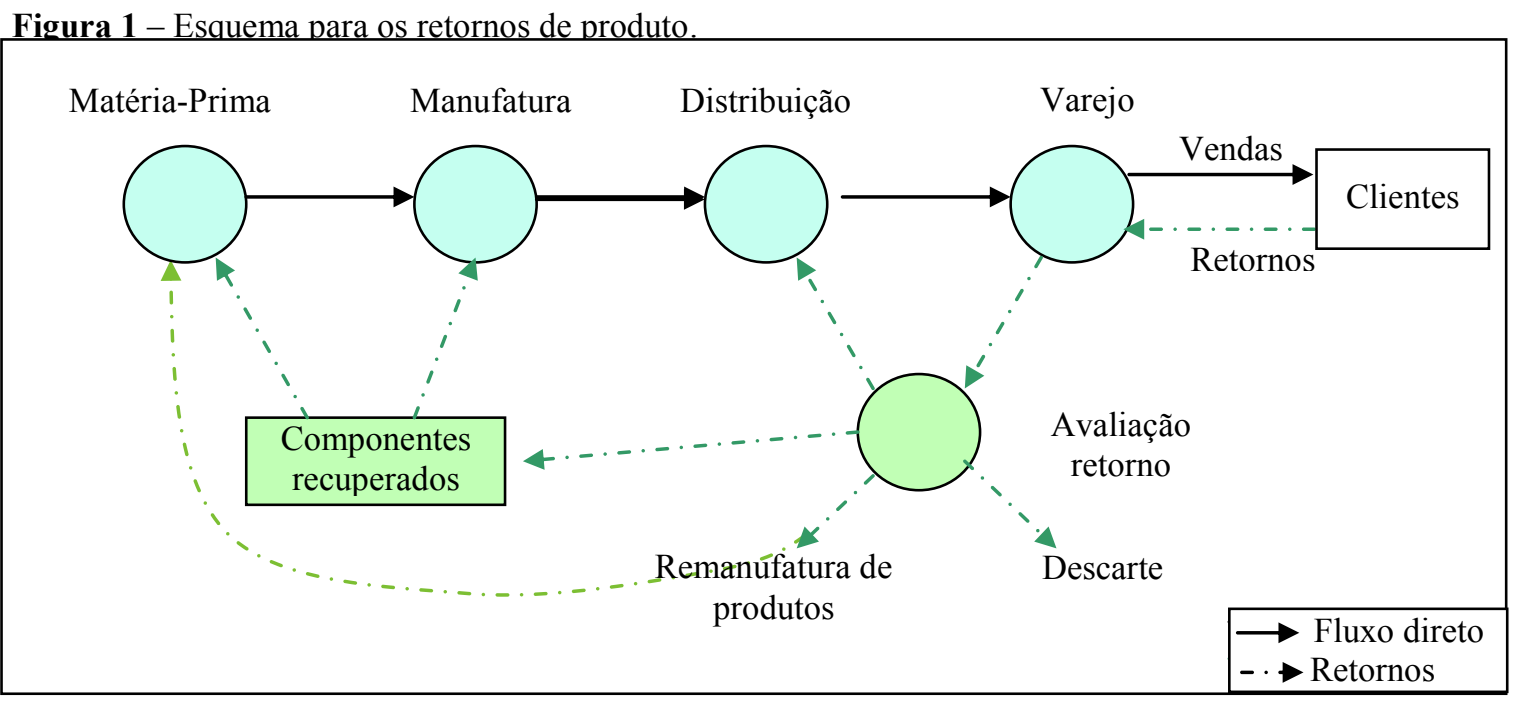

\subsection{Valor do Retorno no Tempo}

Os produtos retornados podem representar um significativo fluxo de bens para muitas empresas. O valor do retorno dos produtos sujeitos à logística reversa para empresas do setor de eletrônicos, por exemplo, poderá chegar a $3 \%$ do faturamento (FIORAVANTE; CARVALHO, 2006). Um fator relevante é que o valor do 
produto em retorno pode diminuir à medida que ele espera por processamento. Produtos de alta tecnologia e ciclo de vida curto perdem mais valor com o passar do tempo, se comparados aos que apresentam ciclo de vida maior. O projeto estratégico de uma empresa com relação a sua CSLF vai ocorrer, portanto, a partir da análise da importância do tempo no valor do retorno como ilustrado na Figura 2.

Como o valor do item em retorno diminui face à obsolescência durante o tempo gasto, a fim de que se torne disponível novamente para uso, os gestores da cadeia devem estar sensíveis ao fato de o tempo representar perda de valor para o produto a ser retornado e utilizar essa informação no projeto da logística reversa. Essa perda, representada pela inclinação das linhas na Figura 2, por unidade de tempo de espera no processo de recuperação, é função dela por obsolescência, somada ao custo de manutenção e gestão do produto em estoque. Está, inclusive, associada às características do produto, ou seja, quanto maior o ciclo de vida, menores serão as perdas por unidade de tempo.

A linha superior, com inclinação negativa, representa a perda de valor do produto novo ao longo do tempo, indicando-se o custo pelo atraso no retorno a um determinado tempo de processamento.

Figura 2 - Valor do retorno no Tempo.

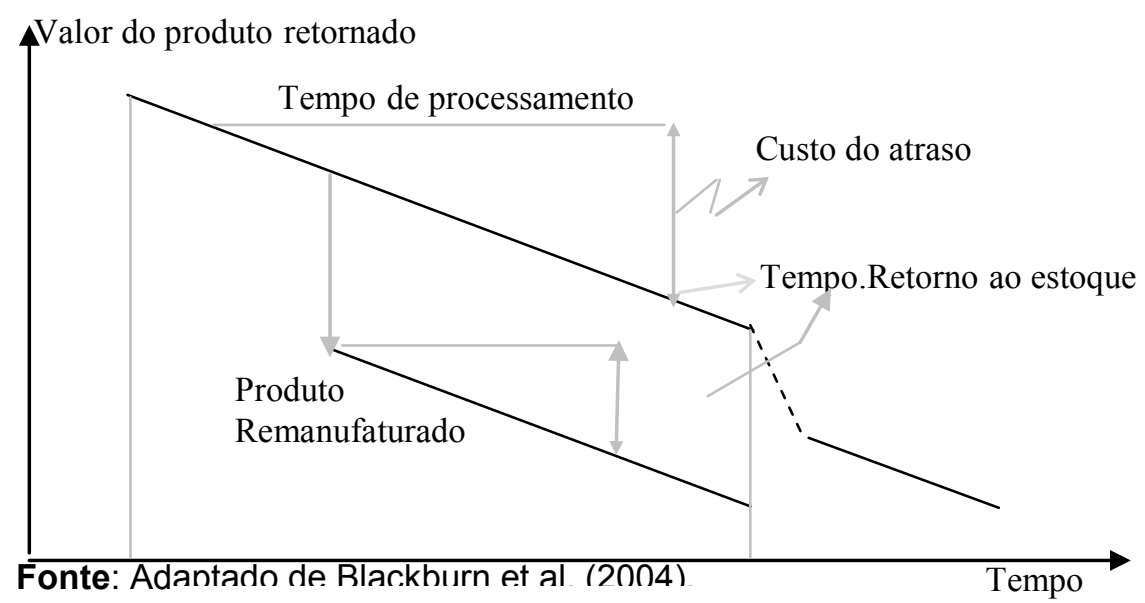

A segunda linha representa a perda de valor do produto remanufaturado ao longo do tempo que tem, também, um custo associado em razão de seu atraso em chegar ao mercado secundário. A inclinação da linha é o Valor Marginal do Retorno no Tempo (VMRT) e representa a perda de valor por unidade de tempo. 
Segundo pesquisa realizada por Blackburn et al. (2004) para o setor eletrônico, os produtos com ciclo de vida muito curto sofrem depreciação em torno de $1 \%$ por semana. O mesmo estudo aponta que o valor de depreciação pode chegar a $20 \%$, no ciclo de recuperação do produto, devido ao tempo de volta ao mercado. Produtos como câmera fotográfica podem apresentar perdas, por exemplo, de $1 \%$ ao mês durante o processo de recuperação de valor. Outros produtos como sucata de ferro, com ciclo de vida maior, apresentam perdas menores, identificadas por menores inclinações nas linhas da Figura 2. Conclui-se que perdas de valor do produto em retorno por unidade de tempo, representadas pela inclinação da curva, são de grande importância no estabelecimento de estratégia para recuperação de valor.

\subsection{Posicionamento Estratégico com Relação ao VMRT}

No item anterior, foi ressaltado que a depreciação de um produto é função de seu ciclo de vida e tempo de retorno. Assim, produtos com ciclo de vida maior podem ter o projeto de uma logística reversa (retorno) diferente daqueles com ciclo de vida menor. Seguindo a taxonomia de Fisher (1997), há para o projeto da logística reversa:

- Logística Eficiente - Logística reversa projetada, tendo como objetivo a minimização do custo. Adequada para produtos com ciclo de vida longo, portanto baixo Valor Marginal do Tempo.

- Logística Rápida - Logística reversa projetada, tendo como objetivo a rapidez de resposta. Adequada para produtos com ciclo de vida curto, portanto alto Valor Marginal do Tempo.

A proposta acima está associada a produtos com baixo e alto valor marginal do tempo do produto em questão. No primeiro caso, o custo logístico é sacrificado, uma vez que se consegue maior rapidez a custos mais elevados, lotes menores, cargas não consolidadas.

Conclui-se que, se a logística reversa de um produto tem de ser eficiente, então, a atividade de avaliação do produto deverá ser centralizada, pois, desse modo, é possível uma economia de escala, organização do transporte em lotes consolidados, etc. Por outro lado, se o objetivo é a rapidez, a atividade de avaliação 
deverá ocorrer de forma descentralizada para minimizar o tempo da logística reversa e a recuperação mais rápida do valor do retorno.

\subsection{Estratégia de Centralização para a Cadeia Reversa Eficiente}

Menores custos logísticos poderão ser obtidos, buscando a eficiência do processo de retorno. Exemplos de produtos que devem adotar esse sistema são as sucatas de ferro e alumínio que têm taxa de depreciação pequena com o tempo ou Baixo Valor Marginal do Tempo (BVMT) e representam grande volume e peso elevado. Para tais produtos, a centralização é o melhor caminho, pois permite a consolidação de cargas. Um esquema para logística com as atividades de teste e avaliação centralizadas é apresentado na Figura 3. A logística de retorno é projetada para economia de escala tanto na atividade de processamento quanto na de transporte do produto. Nela, atividade alguma é desenvolvida no recebimento do produto junto ao varejista e o produto é enviado a um armazém central em lote para testes e avaliação que determinam sua condição e valor. Busca-se a minimização dos custos de operação com o retorno. Após a avaliação, cada um dos produtos é enviado à área adequada (estoque, reparo, desmanche e descarte). Por esse modelo, as atividades de reparo e reconstituição tendem a ser centralizadas e, normalmente, terceirizadas como meio de redução de custos. A estratégia de centralização visa diminuir os custos logísticos e os de restauração de valor para produtos com baixo valor marginal do tempo.

Segundo pesquisa realizada por Blackburn et al. (2004), os tempos típicos de retorno para a empresa de produtos eletrônicos podem chegar a cem dias, ou seja, um posicionamento que privilegia a minimização do custo de processamento à custa de atrasos significativos e perda de valor do retorno. 
Figura 3 - Logística Reversa Centralizada.

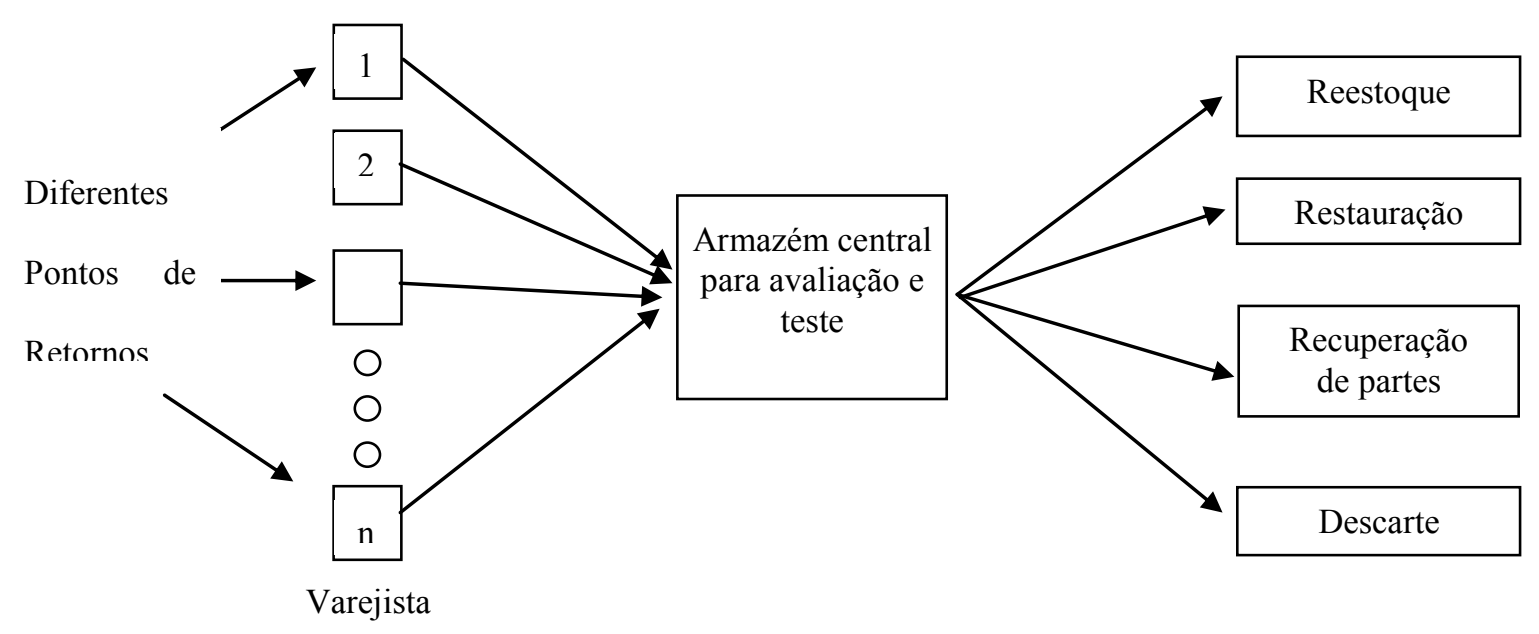

Fonte: Adaptado de Blackburn et al. (2004).

\subsection{Estratégia de Descentralização para a Cadeia Reversa Ágil}

Em logística reversa, existe significativa vantagem em termos de tempo, quando se utiliza a diferenciação antecipada, principalmente, para produtos com Alto Valor Marginal no Tempo (AVMT). Diagnóstico antecipado das condições do produto maximiza sua recuperação de valor, aumentando o valor marginal por devolvê-lo mais rapidamente a seu novo ponto de aquisição. Contrariamente ao conceito de postergação da Logística Direta, em que a diferenciação do produto é adiada para última operação, aqui é utilizado o conceito de antecipação, procurando identificar as condições do produto o quanto antes. A antecipação aumenta o custo operacional e o de implantação por requerer múltiplos pontos para diagnóstico do produto em retorno e sua devolução rápida ao ponto de aquisição de valor.

A Figura 4 ilustra a configuração de uma Cadeia Reversa quando adotada a estratégia de antecipação para quatro condições de retorno: novo, recuperado, para aproveitamento de componentes e para descarte. Nos três últimos casos, o equipamento poderá parecer estar em condições idênticas, contudo deverá ser testado e avaliado para determinar sua condição verdadeira. Pela estratégia de antecipação, precisa ser submetido a um teste de campo para que seja classificado em novo, reparável e descartável. Os que forem classificados como novos poderão voltar imediatamente ao estoque, sem atraso e os reparáveis, enviados a um 
armazém central para futura avaliação e recuperação. No lugar de um único ponto de teste, portanto, a logística reversa rápida deverá ser descentralizada em múltiplos pontos de avaliação dos produtos.

Figura 4 - Logística de Reversa para estratégia descentralizada.

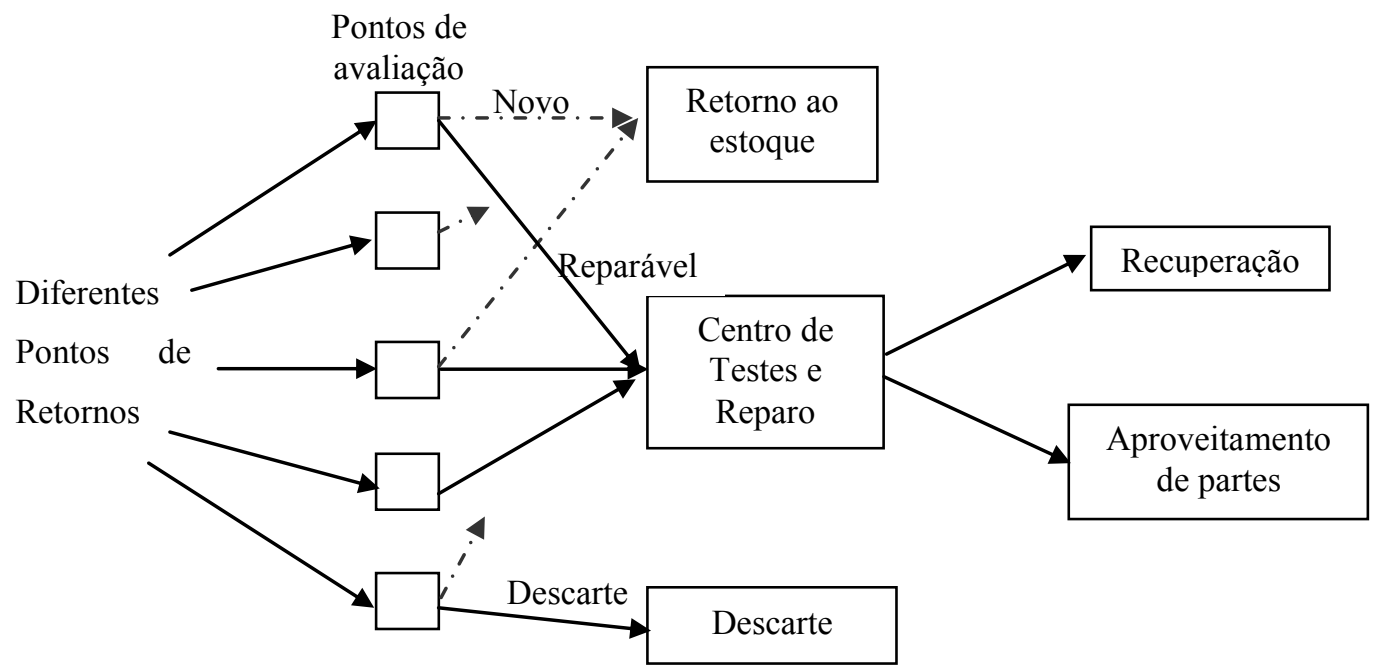

Fonte: Adaptado de Blackburn et al. (2004)

A antecipação poderá aumentar, significativamente, a recuperação de valor do produto com valor marginal de tempo elevado. Na pesquisa realizada na empresa ABC (Blackburn et al., 2004), a redução de perdas de valor em equipamentos novos já é significativa, pois, se o produto novo fosse mandado a um armazém central para testes, perderia em torno de $5 \%$ do valor. Duas questões surgem quando se pensa em descentralização: i) Ela é viável tecnicamente, ou seja, é possível identificar a real condição do produto no campo? ii) Como envolver e motivar o varejista a participar desse processo? Tais questões exigem também o posicionamento da empresa responsável pelo retorno e serão discutidas no estudo de caso.

Uma forma de melhorar o retorno é o uso de sistemas de informação com destaque para o Sistema de Estoque controlado pelo Vendedor (VMI), em que se torna possível identificar, de imediato, o retorno do cliente final. O sistema autogiro implantado pela GM tem o objetivo de auxiliar na logística direta e administrar a logística de retorno para realocar uma peça na cadeia, quando não consumida dentro de um período especificado (CORREA; CAON, 2002, p. 126). 


\section{O ESTUDO DE CASO}

A EMPRESA L atua no mercado de impressão, produzindo e comercializando impressoras, cartuchos e papéis para usuários domésticos e corporativos, em vários canais de distribuição resultantes da combinação produto versus segmento do mercado. A empresa trabalha com produtos de inovação tecnológica e de ciclo de vida curto, o que incentiva a implantação de uma cadeia de suprimentos de laço fechado (KRIKKE, et al.1999). Duas principais perguntas guiaram o estudo de caso:

a) Quais são as principais características, semelhanças e diferenças quanto ao fluxo de retorno de produtos nos dois segmentos de mercado em que a empresa atua (varejista e serviços de impressão)?

b) Quais são as brechas e oportunidades de aplicação dos modelos de CLF nos dois segmentos de mercado em que a empresa atua (varejista e serviços de impressão)?

\subsection{Metodologia}

O estudo de caso deu-se por meio de entrevistas a atores-chave da empresa, principalmente, nas seguintes funções: gerente de logística reversa, gerente de projeto para a iniciativa de logística reversa na America Latina e gerente responsável pela operação de serviços de impressão. Adicionalmente, a empresa disponibilizou acesso a relatórios e sistemas internos para a coleta de dados históricos relacionados a volumes de vendas e retornos. Na primeira fase do trabalho, os pesquisadores realizaram um mapeamento das atividades operacionais da empresa nos dois segmentos de atuação. A seguir, com base na literatura discutida nos capítulos anteriores, realizaram-se comparações e análise de brechas entre os modelos propostos e os operacionais aplicados na empresa. Finalmente, após a revisão dos modelos e da análise com os participantes da empresa, consolidaram-se as sugestões e recomendações de melhoria.

O primeiro passo no estudo de caso foi identificar os produtos e serviços principais para os dois modelos de negócio adotados pela empresa. No setor voltado para atendimento ao usuário corporativo, a EMPRESA L oferece serviço de gerenciamento do parque de impressoras, sendo a responsável por administrar Revista Produção Online. Florianópolis, SC, v.11, n. 4, p. 921-949, out./dez. 2011. 
equipamentos, suprimentos, papéis e recursos humanos necessários para a operação e remoção após o término do contrato ou o fim da vida de cartuchos e impressoras. O produto final para o cliente corporativo é a página impressa e, nesse contexto, a empresa desenvolve um novo modelo de negócio que segue a tendência do mercado de oferecer serviço em complemento à venda de produtos. Fatores que influenciam ativamente na competitividade do produto como componentes de serviços estendidos: contrato adequado à necessidade de cada cliente, continuidade da operação, imagem da empresa prestadora do serviço e atendimento às normas ambientais do cliente e do produto.

No setor varejista, as grandes lojas assumem papel importante na cadeia de suprimentos, servindo como intermediárias, gerenciando toda a interação com os clientes e oferecendo, como produto principal, a solução de impressão que contém impressora e cartucho. Aqui, a variedade de modelos, consultoria para escolha do melhor equipamento, o cumprimento às garantias e possibilidade de desistência entre outros são fatores que influenciam na percepção do cliente, consequentemente, na decisão de compra.

Em ambos os modelos, verifica-se que os serviços estendidos são, de alguma maneira, motivadores para o fluxo reverso com o objetivo final de estabelecer relação entre a percepção do cliente e os modelos de gerenciamento da cadeia reversa.

O passo seguinte foi classificar os retornos tais como:

1. Inconsistência ou danificação de entrega

2. Defeito ou desistência

3. Retornos em Garantias

4. Balanceamento de Estoque

5. Recalls

6. Meio Ambiente

Com essa classificação, analisaram-se os históricos para identificar a incidência e o impacto de cada um dos tipos de retorno a seguir. 


\subsection{Análise de dados para estabelecimento de políticas de retorno}

Pela análise de dados em campo, identificou-se que, em cada um dos modelos, o volume de produtos e suprimentos no fluxo reverso difere consideravelmente. Enquanto no modelo varejista, o volume gira em torno de $2 \%$ (Figura 5.a) das vendas ou entregas a varejistas, no modelo de serviço de impressão, o percentual é de $18 \%$, sobretudo, em razão dos cartuchos coletados após o uso. No modelo varejista, não há essa atividade. Notou-se também que, no modelo varejista, os grandes volumes de retornos estão concentrados no período de garantia (Figura 5.b). No modelo de serviços de impressão, exatamente o fluxo de pós-consumo, consequência do retorno dos cartuchos utilizados, tem a grande participação no total. Assim, todos os processos, desde a malha logística até a configuração dos processos, devem ser adaptados a essa realidade diferente.

Figura 5.a. Percentagem de fluxo reverso sobre entregas

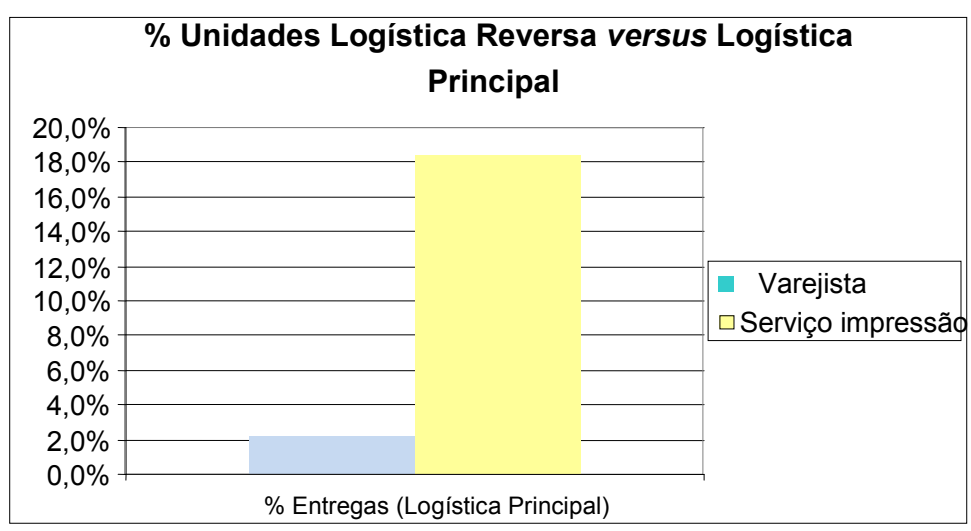

Figura 5.b. Percentagem do fluxo reverso por motivadores.

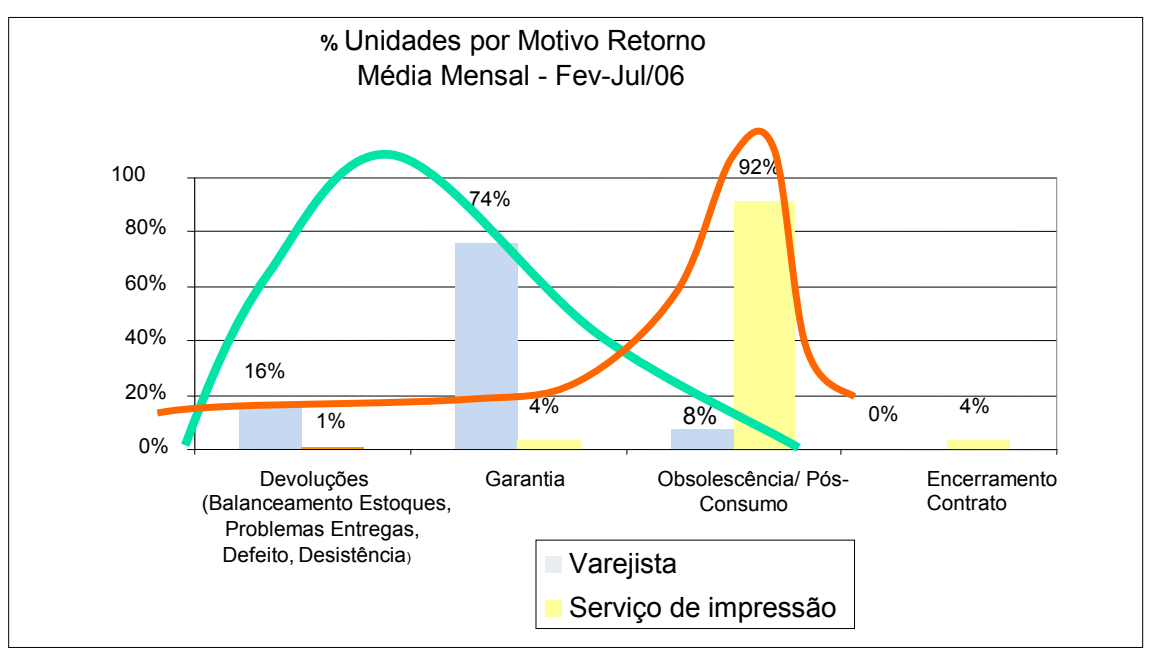

Revista Produção Online. Florianópolis, SC, v.11, n. 4, p. 921-949, out./dez. 2011. 


\subsection{Análise da Operação de Varejo - Usuários Domésticos}

$\mathrm{Na}$ operação de varejo, a Cadeia Reversa é reativa e menos previsível, ocorrendo não como resultado de um planejamento ou de um processo de decisão da empresa, mas em resposta a uma ação do consumidor. A configuração dessa cadeia, apresentada na Figura 6, destaca as atividades que cabem à empresa (Pesquisa e Desenvolvimento, Tecnologia de Informação, Finanças e Marketing) e todas as operações de produção e logística, desde os fornecedores até a entrega do produto ao consumidor final, são terceirizadas.

Essa estratégia de operação é encontrada também no gerenciamento do fluxo reverso, sendo que os processos de logística reversa são executados por parceiros estratégicos da cadeia direta, contudo projetados e operacionalizados sob a supervisão e coordenação de áreas internas da empresa. Para efeito desse estudo, ocorrem os seguintes fluxos reversos: Retornos (pós-venda, até 30 dias após a venda ao cliente final), Garantia (pós-venda, de 30 dias até 1 ano após a venda ao cliente final) e Take Back (processo de pós-consumo, quando o produto retorna em razão de obsolescência ou substituição por um novo modelo) detalhados a seguir.

Figura 6 - Operação de Varejo.

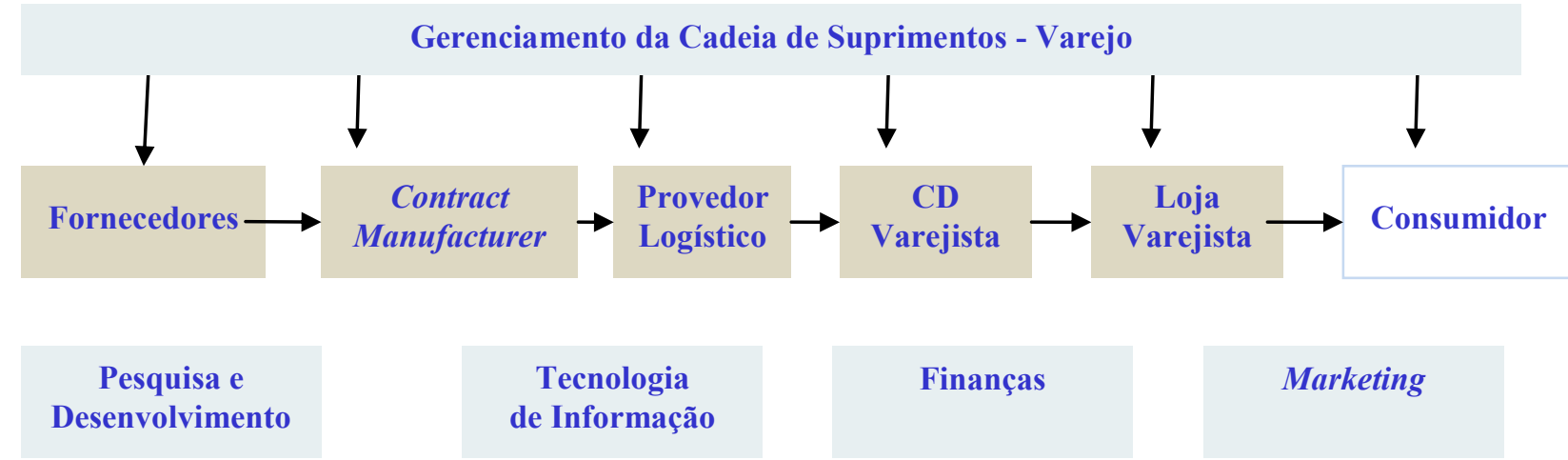

Empresa $\quad$ Terceirizado

\subsubsection{Retornos (até 30 dias após venda ao cliente final)}

Os processos de Retornos são ocasionados, principalmente, pelos seguintes motivadores:

Revista Produção Online. Florianópolis, SC, v.11, n. 4, p. 921-949, out./dez. 2011. 
a) Inconsistência ou dano nas entregas - Representa grande volume de retornos para a EMPRESA L. Isso ocorre quando a quantidade, o valor ou a data da entrega da mercadoria não conferem com a contratada entre o varejista e a EMPRESA L ou quando problemas no transporte geram a recusa do varejista em receber o produto e o consequente retorno ao estoque da EMPRESA L.

b) Defeito ou desistência - Representa o maior volume, cerca de $50 \%$ dos processos classificados como Retornos, e ocorre quando há problema no equipamento, uso incorreto ou simples desistência do cliente. No caso, o produto é retornado pelo cliente final alguns dias após a compra.

c) Balanceamento de estoques - Representa cerca de $10 \%$ dos retornos e ocorre em consequência de uma negociação entre varejistas e a EMPRESA L. Os citados varejistas retornam produtos acumulados em seus estoques em troca da aquisição de novos produtos.

Com base no modelo de Souza et al.(2006), o modelo aplicado é claramente do tipo centralizado/eficiente, uma vez que os retornos são todos centralizados no armazém central, o qual estará representado pelo operador logístico, Figura 7. A maioria dos retornos é classificada como não defeitos e podem voltar à distribuição após uma análise visual e reembalagem.

Os processos aplicados pela EMPRESA L para tratar os produtos que chegam por meio do processo de retorno são:

- Coleta: A coleta dos produtos é feita pelos próprios varejistas ou técnicos certificados pela EMPRESA L. Os pontos de vendas desses varejistas, hoje, representam o único ponto para processos de coleta devido a inconsistências ou danos na entrega.

- Inspeção: Existem dois tipos de inspeção implementadas na EMPRESA L: i) inspeção nos pontos de vendas, que ainda é feita de maneira incipiente e não implementada em todos os pontos; ii) inspeção no armazém. Utiliza-se o mesmo armazém da distribuição dos produtos. 
- Logística Reversa: A logística reversa encarrega-se de trazer o produto desde os pontos de vendas até o armazém e é feita pelas mesmas transportadoras que atendem ao fluxo principal.

- Recondicionamento: O recondicionamento do produto pode ser efetuado no próprio armazém, quando o estado do produto permite que este retorne ao estoque principal ou no Contract Manufacturer, quando uma remanufatura é exigida.

- Disposição: A disposição do produto pode ser o retorno ao estoque ou o envio para substituir produtos retornados em garantia.

Figura 7 - Processo de Retorno até 30 dias.

Retornos

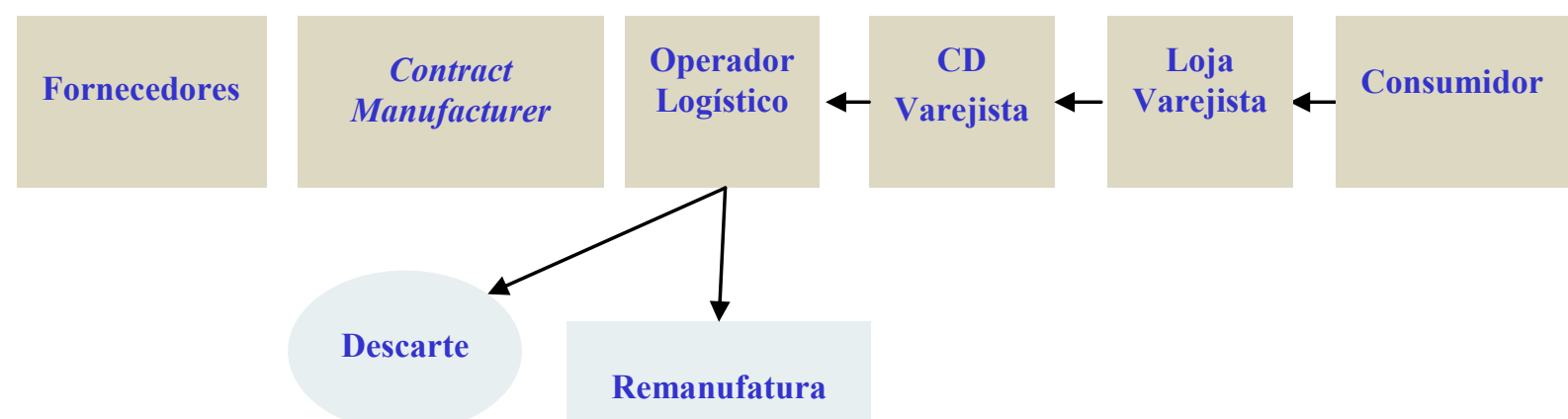

Ao analisar o modelo adotado pela EMPRESA $L$ e considerar que o produto principal (impressoras) tem um ciclo de vida curto e seu valor decai rapidamente com o passar do tempo, conforme os modelos e práticas discutidos anteriormente, ao contrário de focar apenas em eficiência, o modelo de logística reversa deveria priorizar a agilidade com processos de diagnóstico e disposição localizados o mais próximo possível da origem dos retornos.

$\mathrm{Na}$ operação apresentada, o produto passa pelo ponto de atendimento, em seguida, pelo centro de distribuição do varejista, chegando ao armazém do operador logístico, onde estão os processos estruturados de logística reversa. Nesse caso, uma recomendação seria transferir, por meio de treinamento e certificação, parte dos processos localizados nos centros de distribuição para o próprio ponto de venda, buscando o diagnóstico e a tomada de decisão de maneira mais ágil. 


\subsubsection{Garantias (de 30 dias a 1 ano após venda ao cliente final)}

- No fluxo de Garantia, Figura 8, o motivador dos retornos são, obviamente, os retornos em garantia. Verifica-se, assim, uma estrutura Ágil, uma vez que os Centros Autorizados oferecem um processo descentralizado de coleta, inspeção e reparo, evitando-se, em muitos casos, que os produtos retornem aos elos anteriores. Por esse modelo, deverá haver disponibilidade de produtos no centro autorizado para substituição imediata da necessidade do cliente. Os processos de cadeia reversa aplicados na EMPRESA L são as seguintes:

- Coleta: Diferentemente do fluxo de Retornos em que a coleta é feita pelos varejistas, o fluxo de garantia caminha por uma estrutura paralela à cadeia principal por meio das Assistências Técnicas Autorizadas. Todos os produtos que se encontram dentro do período de garantia comprometido pela EMPRESA L e não se aplicam ao Fluxo de Retornos, ou seja, o cliente final comprou há mais de 30 dias, são coletados pela rede de assistência espalhadas pelo País.

- Inspeção: A inspeção é efetuada pela própria assistência técnica que fica responsável por determinar a melhor ação a ser tomada sobre o caso apresentado.

- Logística Reversa: No fluxo de garantia, caso o produto não possa ser reparado na assistência técnica, o cliente irá receber um produto remanufaturado em troca do seu danificado. Toda a logística reversa para entrega do produto remanufaturado na assistência técnica e retorno do produto danificado ao $\mathrm{CM}$ (Contract Manufacturer) é responsabilidade do próprio CM que gerencia as transportadoras. A logística reversa encarrega-se de trazer o produto desde os pontos de vendas até o armazém e é feita pelas mesmas transportadoras que atendem ao fluxo principal.

- Recondicionamento: O produto, nesse caso, mais do que um recondicionamento, passa por um processo completo de remanufatura, cujas peças padrões são trocadas e toda a estrutura da impressora é remanufaturada.

- Disposição: A disposição do produto que retornou de garantia e foi à remanufatura é retornado ao fluxo de garantia para substituir outro produto defeituoso. Caso haja impossibilidade de recuperação, será feita a desmontagem para aproveitamento dos componentes.

Revista Produção Online. Florianópolis, SC, v.11, n. 4, p. 921-949, out./dez. 2011. 
Figura 8 - Processo de Garantias.

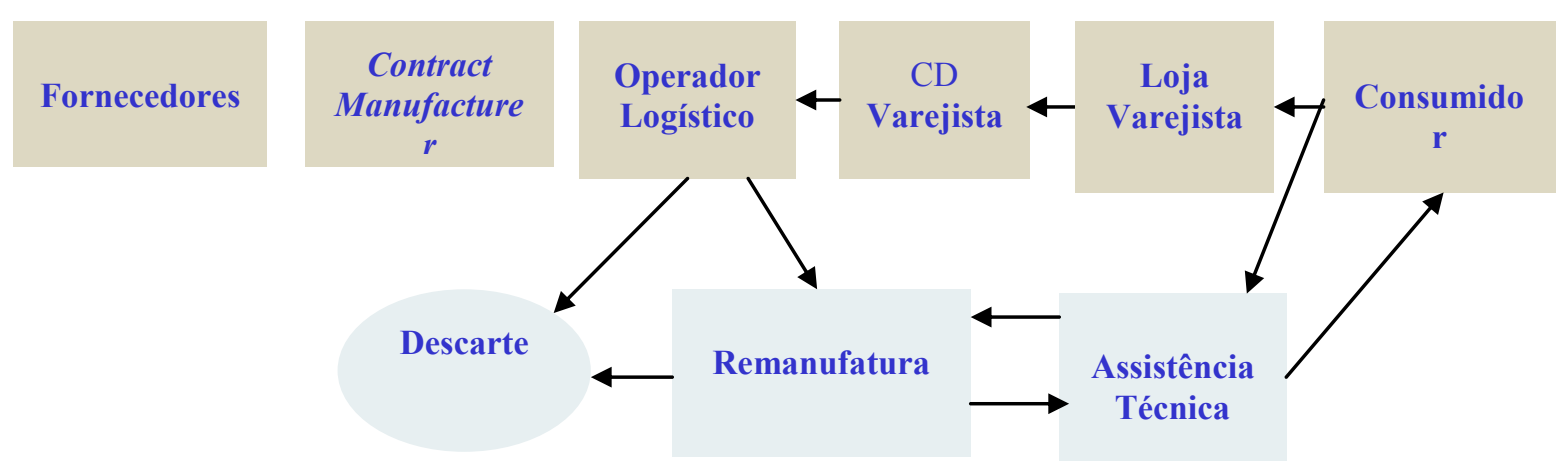

O processo de garantia adota um modelo ágil com a inspeção estruturada nas assistências técnicas (descentralizado). Já, o reparo é executado nos contract manufactures segundo um modelo eficiente. A oportunidade de melhoria identificada nesse modelo refere-se à integração do fluxo de garantia com o fluxo de retornos presentes na citação 6.3.1, pois os mesmos produtos assim retornados poderão ser utilizados como insumos no processo de remanufatura.

\subsubsection{Pós-Consumo (take back)}

Os processos reversos de pós-venda, representados pelos fluxos de retornos e garantias, atendem basicamente a dois objetivos organizacionais: i) redução de custos operacionais e consequente aumento do lucro operacional; ii) satisfação do cliente, oferecendo política de retornos mais liberal e processo de garantia eficiente. Os processos reversos de pós-consumo visam a dois objetivos diferentes: i) alavancagem de receita, uma vez que o retorno dos produtos obsoletos é incentivado e dá o direito ao cliente final de receber um desconto na compra de um produto novo; ii) imagem corporativa. Embora as regulamentações no Brasil ainda não tenham atingido o nível de exigência da Europa ou Estados Unidos, a coleta e reciclagem de produtos ajudam na melhoria da imagem corporativa e está alinhada com a política da empresa de não agressão ao meio ambiente. No fluxo de pósconsumo ou take back, portanto, o motivador dos retornos na EMPRESA L são os retornos de meio ambiente. 
A estrutura estabelecida nesse caso torna-se eficiente, pois o parceiro especializado em reciclagem centraliza todos os processos reversos. Os processos aplicados na EMPRESA L para o fluxo de take-back são os seguintes:

- Coleta: Similarmente ao fluxo de Retornos, no pós-consumo, os varejistas são responsáveis pela coleta. Nesse caso, constitui-se uma ferramenta de marketing muito forte, pois a entrega de um produto obsoleto e/ou danificado permite ao cliente ter desconto na compra de um produto novo, gerando, assim, receita aos varejistas e à EMPRESA $L$ além de atender ao objetivo ecológico de evitar que esses produtos sejam descartados no meio ambiente.

- Inspeção, Logística Reversa, Recondicionamento e Disposição: Para o fluxo de pós-consumo, a EMPRESA L decidiu transferir a uma empresa especializada todos os processos da cadeia reversa. Ela torna-se responsável pela inspeção e logística reversa, coletando os produtos nos varejistas e armazenando-os em suas instalações. O recondicionamento é uma reciclagem, pois os produtos são inteiramente desmontados e a matéria-prima, como plástico e metais, passa a ser vendida em mercados secundários ou destruída, caso não seja possível a reciclagem.

Figura 9 - Processo Pós-Consumo

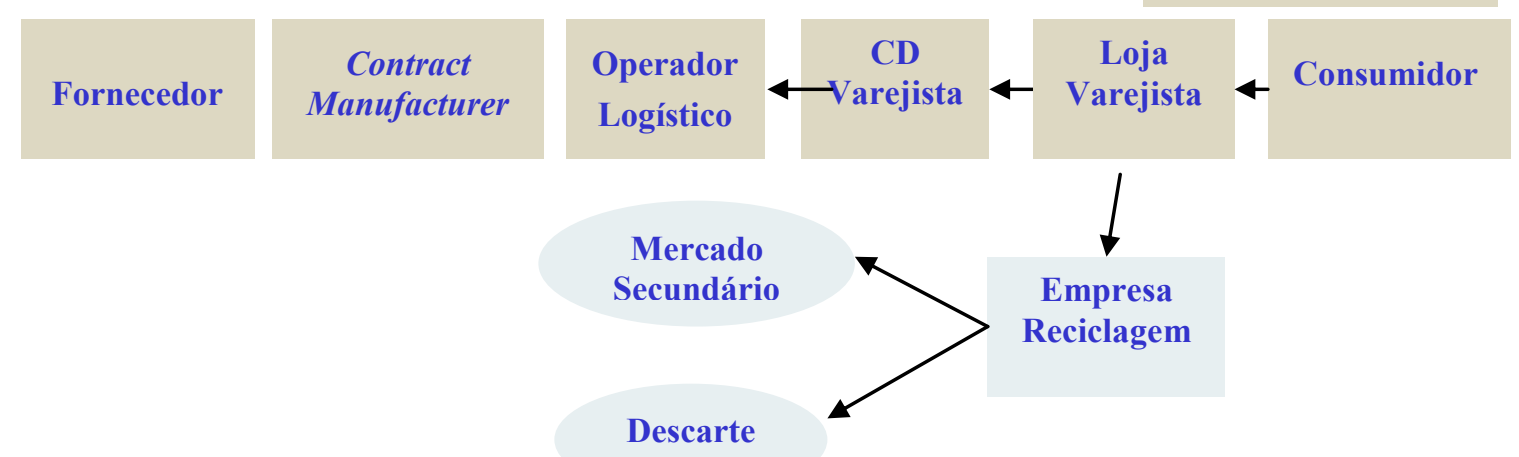

O modelo de take back também está focado em uma estrutura eficiente/centralizada, portanto totalmente terceirizada a um parceiro com know how específico. Os pontos de melhoria, também, nesse modelo referem-se à oportunidade de integrar o fluxo de take back com garantias e retornos, pois um planejamento integrado da logística reversa poderia trazer ganhos adicionais com redução adicional de custos. 


\subsection{Análise dos Serviços de Impressão}

Para a operação de Serviços de Impressão voltados aos usuários corporativos, algumas particularidades podem ser notadas na Figura 10, principalmente, no que se refere à terceirização dos serviços e à transferência de posse dos produtos, como, por exemplo, a presença de uma entidade financeira interna à empresa que tenha um papel na intermediação do direito de uso dos equipamentos na forma de leasing. Nota-se, também, que a operação on-site executada no cliente não é terceirizada totalmente, sendo que os equipamentos e suprimentos disponibilizados nesse site são ainda de propriedade da EMPRESA L.

Para o modelo de negócio de Serviços de Impressão, o volume de produtos retornados no processo de take back é muito maior que o modelo varejista. Os outros processos, como devoluções e garantias, são mínimos ou quase inexistentes.

A quase inexistência de retornos ou processos de garantia justifica-se pela característica da operação que conta, em sua maioria, com técnicos especializados da empresa $L$ para, no site dos clientes, executarem reparos e/ou ajustes antes que tais eventos sejam gerados.

Figura 10- Operação de Serviços de Impressão.

Gerenciamento da Cadeia de Suprimentos - Impressão

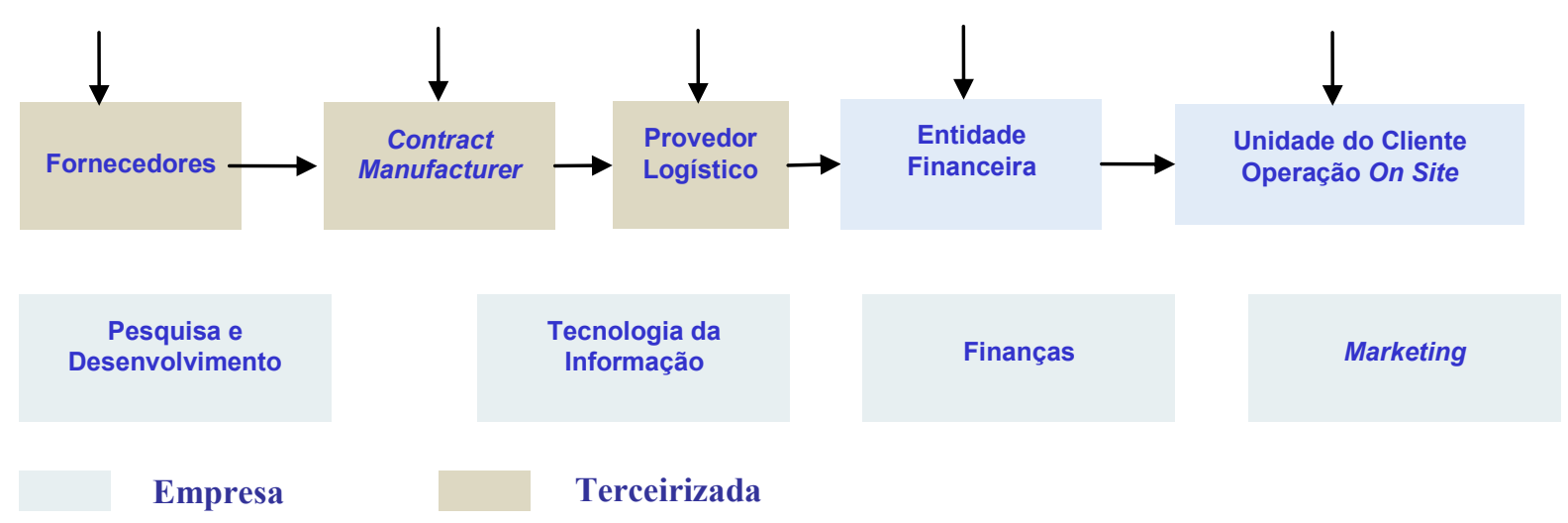

Por sua vez, a composição do modelo operacional, que inclui uma entidade financeira intermediando a posse do produto, faz com que o fluxo de equipamentos retornados depois de uso (take back) seja relevante, mas do ponto de vista operacional esses processos são tratados de maneira independente da operação 
principal e sem aparente estruturação. No momento de realização da pesquisa, a entidade financeira responsável pelos equipamentos planeja iniciar a estruturação dos processos de tratamento de retornos e remarketing. A empresa, entretanto, não identificou ainda um modelo estruturado de logística reversa na operação de serviços de impressão e nenhum dos três modelos descritos no artigo para as operações de varejo aplicam-se a esse caso.

Para melhor compreensão das necessidades e características da Cadeia Reversa neste modelo de negócio, realizou-se análise das informações disponíveis referentes aos volumes e características dos produtos circulando nessa rede.

\section{CARACTERÍSTICAS E RECOMENDAÇÕES PARA A CADEIA REVERSA NA EMPRESA}

\subsection{Análise das características dos dois modelos}

A partir da análise das operações de Serviços de Impressão, desenvolveu-se uma análise comparativa (Quadro 1) entre os dois modelos de negócios da EMPRESA L nas três dimensões mais críticas da Cadeia Reversa: os Motivadores, as Características dos processos de retornos e a Rede logística mais efetiva para o gerenciamento do fluxo reverso. 
Quadro 1 - Comparação da Cadeia Reversa nos modelos Varejista e Serviços de Impressão.

\begin{tabular}{|c|c|c|}
\hline & Varejista & Serviços de Impressão \\
\hline Motivadores & $\begin{array}{l}\text { Balanceamento Estoque Varejo } \\
\text { Problemas na Entrega } \\
\text { Defeito no Uso do Equipamento } \\
\text { Desistência } \\
\text { Garantia } \\
\text { Obsolescência/Pós-Consumo/ } \\
\text { Meio Ambiente - Imagem }\end{array}$ & $\begin{array}{l}\text { Balanceamento Estoque } \\
\text { Suprimentos } \\
\text { Defeito no Uso do Equipamento } \\
\text { Upgrade } \\
\text { Encerramento de Contrato } \\
\text { Suporte } \\
\text { Obsolescência/Pós- Consumo/ Meio } \\
\text { Ambiente - Requisito Legal }\end{array}$ \\
\hline Características & \begin{tabular}{|l|} 
Retorno do Estoque \\
Permite Consolidação \\
Produtos Propriedade Varejistal \\
Usuário Final \\
Falta de Previsibilidade Demanda \\
Retorno de Equipamentos é \\
contínuo \\
Foco Processos de Pós-Venda \\
Satisfação Cliente Final e e \\
Parceiros
\end{tabular} & $\begin{array}{l}\text { Retorno de uma Ordem } \\
\text { Não Permite Consolidação } \\
\text { Produtos Propriedade EMPRESA L } \\
\text { Previsão da Demanda mais } \\
\text { acessível (depende do consumo } \\
\text { equipamentos) } \\
\text { Retornos de Equipamentos é pontual } \\
\text { (início e término de contrato) } \\
\text { Focos Processos Pós-Consumo }\end{array}$ \\
\hline Processo/Rede & $\begin{array}{|lcr|}\text { Processos de } & \text { Coleta } & \text { feitos pelo } \\
\text { Varejista } & & \\
\text { Predomina } & \text { a } & \text { Estrutura } \\
\text { Centralizada } & & \end{array}$ & $\begin{array}{l}\text { Processo de Coleta efetuado pelos } \\
\text { Funcionários EMPRESA L } \\
\text { Estrutura Descentralizada favorece } \\
\text { Nível de Serviço }\end{array}$ \\
\hline
\end{tabular}

\subsection{Diagnóstico e Recomendações}

Este artigo analisou o caso das cadeias de suprimento de laço fechado, ou seja, aquelas em que os produtos vão até o consumidor final e voltam para serem aproveitados ou terem um descarte adequado com relação ao meio ambiente. Em particular, considerou o setor de serviços de impressão que foi classificado em usuários corporativos (serviços) e usuários domésticos (varejistas).

Realizou-se um diagnóstico do gerenciamento da cadeia reversa no modelo de serviços de impressão e dos modelos para o tratamento dos retornos. Tais modelos foram classificados em centralizados ou descentralizados de acordo com a depreciação do retorno no tempo. Aos usuários corporativos, os retornos manifestam-se com mais intensidade devido à obsolescência e pós-consumo, recomendando-se adotar a logística reversa centralizada. Aos usuários domésticos, acentua-se a característica de resposta rápida para atendimento do nível de serviço desejado pelo consumidor.

Revista Produção Online. Florianópolis, SC, v.11, n. 4, p. 921-949, out./dez. 2011. 
Para o estudo de caso da EMPRESA L, verificou-se que os motivadores estão relacionados a requisitos legais do cliente (externo) e a empresa não tem uma cadeia de pós-consumo totalmente desenvolvida, talvez, por questão de uma legislação mais fraca no tocante ao caso. Constatou-se, também, que a empresa passa a terceiros, principalmente no caso usuários domésticos, a responsabilidade pelas operações logísticas na expectativa de que contribuirá, assim, para a melhoria do serviço ao consumidor. Ao mesmo tempo, tal posicionamento oferece possibilidade de a contract manufacturer conhecer, analisar as principais causas de defeito e trabalhar para corrigir o processo de produção.

Há, ainda, recomendações à EMPRESA L, objetivando-se melhora no processo de sua cadeia de laço fechado. Destacam as seguintes necessidades: i) estabelecimento de processos específicos para o encerramento de contratos (reduzir tempo, risco fiscal e imagem corporativa); ii) utilização de equipe para padronizar os processos de coleta, aumentar chance de recuperação do produto e melhorar percepção do cliente; iii) desenvolvimento de um sistema de previsão da demanda de coleta do retorno com base no consumo; iv) implantação de um modelo de logística ágil para os retornos que ocorrem até um mês após a compra; v) desenvolvimento de uma análise dos impactos da expansão da logística reversa de pós-consumo para um modelo descentralizado e do fracionamento da coleta.

\section{REFERÊNCIAS}

AVIV, Y.; FEDERGRUEN, A.; Capacitated multi-item Inventory systems with random and seasonally fluctuating demands: Implications for Postponement Strategies Management Science, v. 47, n. 4, Apr. p.512-531, 2001.

BLACKBURN J.; GUIDE, D.; SOUZA, G.; WASSENHOVE, L. Reverse supply chains for commercial returns, California Management Review , v.46, n.2, p. 6-18, 2004.

BOWERSOX; D. CLOSS; D. COOPER, M.; Gestão da cadeia de suprimentos e logística. 2. ed. Rio de Janeiro: Campus, 2008.

CORREA, H.L; CAON, M. Gestão de serviços: lucratividade por meio de operações de satisfação dos clientes. São Paulo: Atlas, 2002.

FERRENDIER, S; MATHIEUX, F.; REBITZER, G.; SIMON, M.; FROELICH,D.; Environmentally improved product design case studies of the european electrical and electronics industry, july 2002. Disponível em: 
$<$ www.ihrt.tuwien.ac.at/sat/ baseecolife/ ecodesign guide 20> version 3L07_2002. pdf.

FIORAVANTE, R.; CARVALHO, M.. Visão Sistêmica para a Cadeia Reversa: Um estudo de caso no ramo de Produtos Eletrônicos. In: SIMPÓSIO DE ADMINISTRAÇÃO DA PRODUÇÃO, LOGÍSTICA E OPERAÇÕES INTERNACIONAIS, 9, 2006, São Paulo. Anais... São Paulo, 2006.

Aplicações de modelos de cadeia reversa em uma operação de serviços: estudo de caso no setor de serviços de impressão In: SIMPÓSIO DE ADMINISTRAÇÃO DA PRODUÇÃO, LOGISTICA E OPERAÇÕES INTERNACIONAIS, 11, 2008. Anais...

FISHER, M. What is the right supply chain for your product, Harvard Business Review, v. 75, n. 2, p. 83-93, march/April 1997.

GUIDE, D. H. and VAN WASSENHOVE. L.N., L.N. Van. The reverse supply chain. Harvard Business Review , p 25-26, 01 Feb 2002.

The challenge of closed-loop supply chains, Interfaces, v. 33, n. 6, p 3-6, November/December 2003. Disponível em: <http://producaoonline.org.br/index.php/rpoe> Acesso em: 18 out. 2010.

KRIKKE, H.R.; HARTEN, A.; SCHUUR, P.C. Business case Océ:Reverse logistic network re-design for copiers, OR Spektrum, v. 21, p.381- 409, 1999.

KONSTANTARAS ; PAPACHRISTOS. A note on developing an exact solution for an inventory system with product recovery. International Journal of Production Economics. V. 111, n.2, p.707-712, 2008.

LEBRETON, B. Strategic closed-loop supply chain management: lectures notes in economics and mathematical systems. Berlin: Springer, 2007.

LEE, H.L.; PADMANABHAN, V.; WHANG, S. Information distortion in a supply chain: the bullwhip effect. Management Science. Chicago, USA, v. 43, p. 546-558, 1997.

MOLLENLOPF, D.A.; CLOSS, D. J. The Hidden Value in Reverse Logistics, Supply Chain Management Review, p. 12-16, July/August 2005.

PIRES, S.; Gestão da cadeia de suprimentos:_conceitos, estratégias, práticas e caso. São Paulo: Atlas, 2004.

RAJAGOPALAN, S.; Methodology for reverse supply chain desing in consumer electronic industry. Dissertação de Doutorado, University of Texas at Arlington, 2006.

ROGERS, D.;TIBBEN-LEMBKE, Going Backwards: reverse logistics trends and practices, reverse logistics council, 1998. 
RYDER. Reverse logistics from black hole to untapped revenue stream supply chain management review. Disponível em: http://www.scmr.com/article/reverse logistics from black> hole_to_untapped_revenue_stream. Acesso em: $05 \mathrm{fev}$. 2011.

SIMCHI-LEVI, D.; KAMINSKY, P. AND SIMCHI-LEVI,E - Designing and managing the supply chain - concepts, strategies, and case studies. Rio de Janeiro: McGrawHill, 2000.

SOUZA, G.; GUIDE, D.; WASSENHOVE, L.; BLACKBURN, J. Time Value Of Commercial product Returns, Management Science, v. 52, n. 8, p 1200-1214, August 2006.

STEVENS. G. Integrating the Supply Chain Journal of Physical Distribution and Material Management, n.8, p 3-8, 1989.

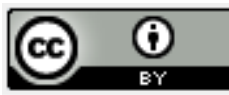

Artigo recebido em 05/04/2010 e aceito para publicação em 28/11/2011 